\title{
Interrelation of microstructure and thermodynamic parameters in TiNi alloy during multiple martensitic transformations
}

\author{
Anna Churakova ${ }^{1,2 *}$ \\ ${ }^{1}$ Institute of Molecule and Crystal Physics - Subdivision of the Ufa Federal Research Centre of the \\ Russian Academy of Sciences, 151 pr. Oktyabrya, 450075, Ufa, Russia \\ ${ }^{2}$ Ufa State Aviation Technical University, 12 K. Marx str., 450008, Ufa, Russia
}

\begin{abstract}
The effect of multiple martensitic transformations on the microstructure and thermodynamic parameters of the alloy of the TiNi system was investigated. It was shown that in the $\mathrm{Ti}_{50} \mathrm{Ni}_{50}$ alloy, with an increase in the number of thermal cycles with rapid heating and cooling up to $\mathrm{n}=100$, a consistent increase in the dislocation density occurs, and a decrease in the width of martensitic plates is observed. And also, that in TCs with fast heating and cooling of the $\mathrm{Ti}_{50} \mathrm{Ni}_{50}$ alloy in a coarse-grained state, a change in the trend in the temperatures of martensitic transformations is observed - with an increase in the number of thermal cycles to $n=50$, they decrease, and at $n>50$ the temperatures increase.
\end{abstract}

\section{Introduction}

The alloys based on titanium nickelide (TiNi) belong to the class of functional materials with shape memory effects (SME) caused by thermoelastic martensitic transformations B2 B19' occurring in the temperature range close to room temperature [1-4]. These alloys are widely used in the medicine and technology. It is known that the cycle of martensitic transformations (MT) upon cooling and heating leads to the generation of dislocations in the crystal lattice. So, in TiNi alloys, during multiple MT cycles, a certain increase in the dislocation density occurs, which, in turn, is accompanied by a change in the temperatures of martensitic transformations and a certain increase in the dislocation yield strength of the alloys under mechanical loading [5-7].

However, for TiNi alloys, thermal cycling is not used to increase the yield strength as such, but using thermal and mechanical cycling it is possible to "induce" a multiple shape memory effect in TiNi for special applications. A rather large number of works has been devoted to the influence of thermal cycling (TC) on the structure and properties of TiNi alloys. But at the same time, studies of the effect on TiNi alloys were carried out in a limited number [8-11] and, an unambiguous dependence on the temperature changes of martensitic transformations and shape memory effects in TC was not established.

\footnotetext{
* Corresponding author: churakovaa_a@mail.ru
} 
In the article [6], which is devoted to the study of phase hardening and the evolution of the crystal structure during MT in titanium nickelide of various chemical compositions, it was found that thermal cycling increases the yield strength and the strain hardening coefficient. Depending on the number of thermal cycles, the temperature Ms shifts predominantly toward lower temperatures; however, no noticeable temperature changes were detected in the alloy with a high Ni content with respect to stoichiometry, which is consistent with data obtained by other authors. With an increase in the number of MT cycles, the characteristics of phase hardening change monotonously and approach saturation at 20-30 cycles. With further cycling, not only the temperature at which the direct transformation begins, but also other martensitic points remain unchanged. Thus, the effect of stabilization of the hysteresis loop with an increase in the number of cycles was discovered. In this paper, we will investigate the relationship of the microstructure and thermodynamic characteristics of the TiNi alloy.

\section{Material and methods}

As the study material it chose a two-component alloy of the TiNi system - an alloy of the equiatomic composition $\mathrm{Ti}_{50} \mathrm{Ni}_{50}$, which has the structure of $\mathrm{B}^{\prime} 9^{\prime}$-monoclinic martensite at room temperature, the transformation temperatures are $\mathrm{Ms}=63{ }^{\circ} \mathrm{C}$, Mf $=40{ }^{\circ} \mathrm{C}$, As $=94$ ${ }^{\circ} \mathrm{C}$, Af $=110{ }^{\circ} \mathrm{C}$. To form a solid solution the TiNi alloy were quenched from the homogeneity region (from $800{ }^{\circ} \mathrm{C}$ ) in water.

Thermal cycling on the samples in different initial states is performed via consecutive dipping of samples in liquid nitrogen $\left(-196^{\circ} \mathrm{C}\right)$ with subsequent heating to $1508 \mathrm{C}$ on the electric heater, which respectively is lower and higher than the temperatures of direct and reverse martensitic transformations. Samples with a section of less than $1 \mathrm{~mm}$ are subjected to thermal cycling, which ensures quick heating and cooling of samples. The number of thermocycles "heating-cooling" varies from 0 to 100. The dwell time for heating and cooling is 5 minutes. The fine structure of the material was studied with a JEM-2100 transmission electron microscope (TEM) at an accelerating voltage of $200 \mathrm{kV}$. The foils for electron-microscopic studies were prepared on a TenuPol-5 twin jet electropolishing set according to the standard procedure with the help of the electrolyte $10 \% \mathrm{HClO}_{4}+$ $90 \% \mathrm{CH}_{3}\left(\mathrm{CH}_{2}\right)_{3} \mathrm{OH}(90 \%$ butanol). The voltage was $50 \mathrm{~V}$. The calorimetric studies are implemented on the differential scanning calorimeter Netzsch DSC 204 F1 Phoenix on samples of $50 \mathrm{mg}$ (diameter of $3.5 \mathrm{~mm}$, thickness of $0.5 \mathrm{~mm}-0.7 \mathrm{~mm}$ ) during cooling and heating in the temperature range from -150 to $150{ }^{\circ} \mathrm{C}$ with a rate of $20^{\circ} \mathrm{C} / \mathrm{min}$. The transformation temperatures are determined by the tangent method (standard ASTM 200405), the energy of transformations is determined via the area under the calorimetric peak of the differential scanning calorimetry.

\section{Results and discussions}

In the initial quenched state in the $\mathrm{Ti}_{50} \mathrm{Ni}_{50}$ equiatomic alloy, large austenitic grains with a size of about $200 \pm 10 \mu \mathrm{m}$ with distinct boundaries are observed (Fig. 1, a). According to the results of optical metallography, a surface relief is found inside them in the form of many parallel stripes of the martensitic plates (Fig. 1, b). 


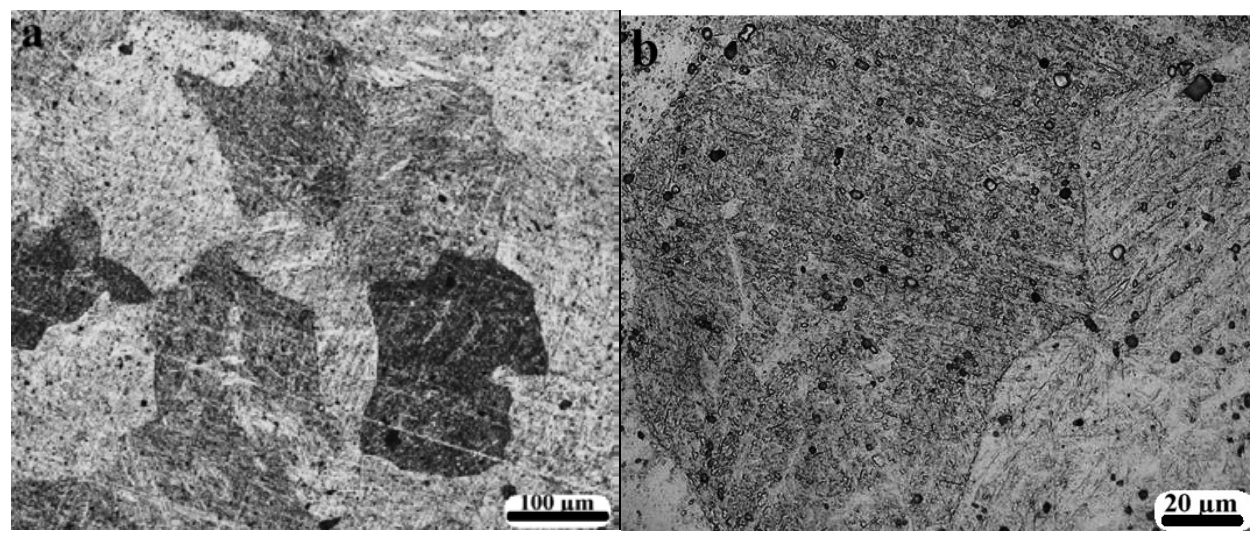

Fig. 1. Microstructure of the alloy $\mathrm{Ti}_{50} \mathrm{Ni}_{50}$ in the quenched state (OM). Figure $b$ shows a section with a large magnification and a martensitic relief.

The transmission electron microscopy analysis shows that the alloy has martensite microstructure at room temperature with mainly package morphology of paired twin plate crystals B19', which are twins (111) and (011) B19' of the I type (on the whole it is typical of binary TiNi alloys). The width of twin martensite plates $h_{M}$ is $85 \pm 15 \mathrm{~nm}$, the boundaries between martensite crystals are clear and free of defects, Fig. 2.

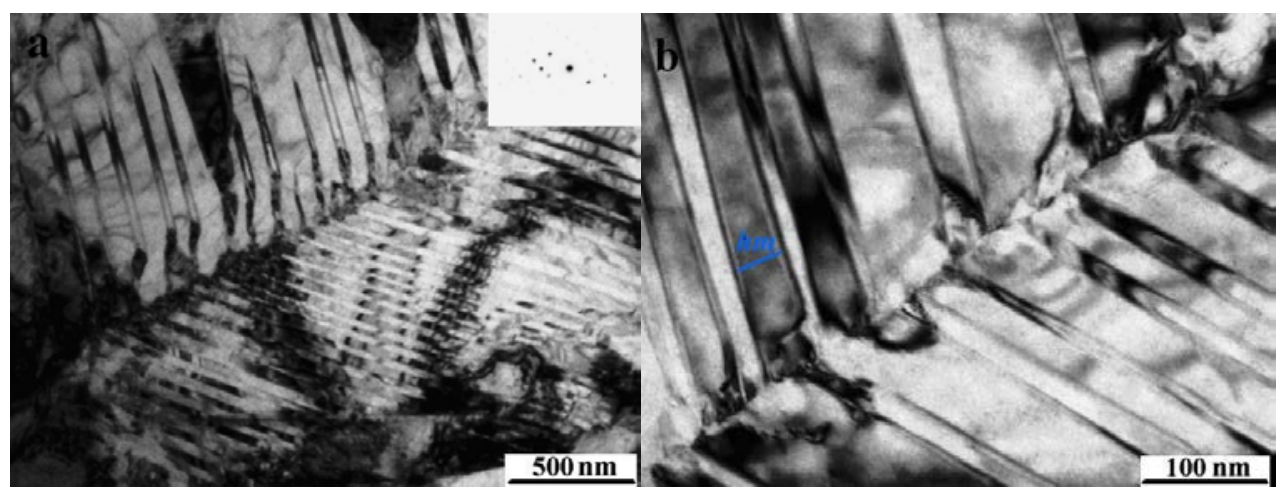

Fig. 2. Typical TEM images of the microstructure of B19'-martensite of Tiso Ni50 alloy in the coarsegrained state.

Thermal cycling with consecutive increase of the number of cycles results in enhancement of the dislocation density and successive decrease of the martensite plate width, Table 1. After thermal cycling in the temperature range MT B2 $\rightarrow$ B19 'with a number of cycles equal to 20 in a microstructure consisting mainly of plate martensite, a complex dislocation substructure arises in some regions. With an increase in the number of thermal cycles from 20 to 50, developed dislocation clusters are observed in this state, forming the so-called "dislocation forest". Filming from various sections of the foil revealed the first composite nanotwins and stacking faults formed inside the martensite twins (h (001) B19 '= $12 \pm 3$ $\mathrm{nm})$. The width of the martensite plates decreases to $\mathrm{h}_{\mathrm{M}}=65 \pm 10 \mathrm{~nm}$.

In the state after thermal cycling with the maximum number of thermocycles, the

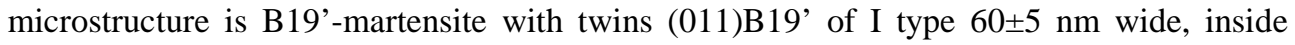
which composite nanotwins (001)B19' several nanometers wide ( 101 nm) and formed during thermal cycling are observed, Fig. 3. 


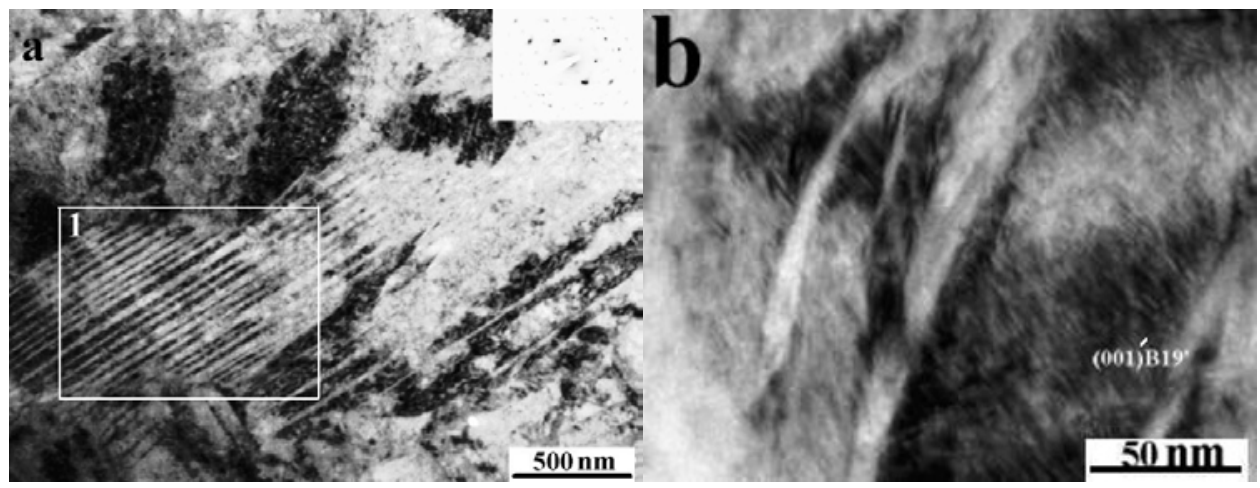

Fig. 3. Typical microstructure of coarse-grained $\mathrm{Ti}_{50} \mathrm{Ni}_{50}$ alloy after 100 thermocycles, (b) displays composite nanotwins (001)B19'

Table 1. The results of TEM analysis of the sizes of structural elements in various states of the alloy $\mathrm{Ti}_{50} \mathrm{Ni}_{50}$

\begin{tabular}{|c|c|c|}
\hline State & $\begin{array}{c}\text { Size of structural elements / width of } \\
\text { martensitic twins, } \mathbf{n m}\end{array}$ & $\begin{array}{c}\text { Presence / type, width of } \\
\text { nanotwins, nm }\end{array}$ \\
\hline CG $\mathbf{n = 0}$ & $85 \pm 15$ & - \\
\hline CG $\mathbf{n}=\mathbf{2 0}$ & $81 \pm 10$ & - \\
\hline CG $\mathbf{~ n = 5 0}$ & $65 \pm 10$ & $12 \pm 3(001) \mathrm{B} 19$ \\
\hline CG $\mathbf{n}=\mathbf{1 0 0}$ & $60 \pm 5$ & $10 \pm 1(001) \mathrm{B} 19$ \\
\hline
\end{tabular}

The authors of [6] studied of the effect of thermal cycling on TiNi alloys, showed that the Ms of an alloy with a lower Ni content relative to stoichiometry decreases by about $20{ }^{\circ} \mathrm{C}$ as a result of thermal cycling, and the Ms of Ni-enriched alloys practically does not change. In the work [12] by the DSC method, it was found that thermal cycling leads to a decrease in the temperatures of martensitic transformations in the CG state by $3-6{ }^{\circ} \mathrm{C}$, in the UFG state of a TC it leads to a slight decrease in the temperatures of direct transformation $\left(\mathrm{M}_{\mathrm{s}}\right.$, $\mathrm{M}_{\mathrm{f}}$ ) by $2-3{ }^{\circ} \mathrm{C}$ and an increase return temperatures (As, Af) by about $6{ }^{\circ} \mathrm{C}$. A decrease in the temperatures of the peaks of the forward and reverse transformations is also observed, and the change in the enthalpy of transformation has a multidirectional character.

According to the data obtained, during direct martensitic transformation (DMT) (cooling at $150{ }^{\circ} \mathrm{C}$ ), one clear exothermic peak appears on the DSC curves; during the reverse martensitic transformation (RMT), an endothermic peak is observed associated with the appearance of the high-temperature austenitic phase B2 from the martensitic phase B19' (point $\left.A_{s}\right)$. The transformation energies $\left(Q_{\text {dir }}, Q_{\text {res }}\right)$, defined as the areas under the DSC curves, change little during phase transitions for the states under consideration. In turn, this indicates that the phase transformation process in the alloy with a CG structure proceeds more intensively, which may be related to the size of the structural elements and the values of internal stresses.

As a result of repeated phase transformations in the alloy, the transformation temperatures shift to the region of lower temperatures. This change is due to the accumulation of defects in the structure, which impede the occurrence of the transformation. Peak transformation temperatures $\left(M_{s}, A_{s}\right)$, which indirectly indicate the hysteresis of the transformation, change similarly to the temperatures of the beginning and end of the transformation (Table 2). 
Table 2. Differential scanning calorimetry data for MT temperatures

\begin{tabular}{|c|c|c|c|c|c|c|c|c|c|c|c|}
\hline & \multirow{3}{*}{ State } & \multicolumn{10}{|c|}{ Temperature, ${ }^{\circ} \mathrm{C}$} \\
\hline & & \multirow{2}{*}{$\mathbf{M}_{\mathrm{s}}$} & \multirow{2}{*}{$\mathbf{M}_{\mathbf{f}}$} & \multirow{2}{*}{$\mathbf{A}_{\mathrm{s}}$} & \multirow{2}{*}{$\mathbf{A}_{\mathbf{f}}$} & \multirow{2}{*}{$T_{0}^{s}$} & \multicolumn{2}{|c|}{$\mathbf{T}_{\mathbf{p}}$} & \multirow{2}{*}{$\begin{array}{c}\mathbf{M}_{\mathrm{s}-} \\
\mathbf{M}_{\mathbf{f}}\end{array}$} & \multirow{2}{*}{$\begin{array}{l}\mathbf{A}_{\mathbf{f}} \\
\mathbf{M}_{\mathrm{s}}\end{array}$} & \multirow{2}{*}{$\begin{array}{c}\mathbf{A}_{\mathrm{s}}- \\
\mathbf{A}_{\mathrm{f}}\end{array}$} \\
\hline & & & & & & & $\mathbf{M}_{\mathbf{p}}$ & $\mathbf{A}_{\mathrm{p}}$ & & & \\
\hline \multirow{4}{*}{$\begin{array}{l}\text { U } \\
+ \\
+\end{array}$} & $\mathrm{n}=\mathbf{0}$ & 63,4 & 40,7 & 94,0 & 110,0 & 86,7 & 50,3 & 102,7 & 22,7 & 46,6 & 16 \\
\hline & $\mathrm{n}=\mathbf{2 0}$ & 58,0 & 20,0 & 69,8 & 100,2 & 79,1 & 35,1 & 87,2 & 38,0 & 42,2 & 30,4 \\
\hline & $\mathrm{n}=\mathbf{5 0}$ & 55,3 & 16,0 & 65,0 & 97,5 & 76,4 & 34,9 & 85,0 & 39,3 & 42,2 & 32,5 \\
\hline & $\mathbf{n}=\mathbf{1 0 0}$ & 61,8 & 39,9 & 93,6 & 104,5 & 83,15 & 49,3 & 100,5 & 21,9 & 42,7 & 10,9 \\
\hline
\end{tabular}

Such a change in temperature can be explained as follows: on the one hand, the temperature MT decreases, since there is an accumulation of dislocations that impede the movement of the phase boundary. On the other hand, it is known that increased internal stresses can initiate a martensitic transformation. The mutual influence of these factors determines the complex behaviour of temperature points during thermal cycling. The dependences of the change in the transformation energies on the number of TC cycles have the identical form of the transformation temperature graphs (Fig. 4). A similar pattern of behaviour can be explained similarly to temperature changes.

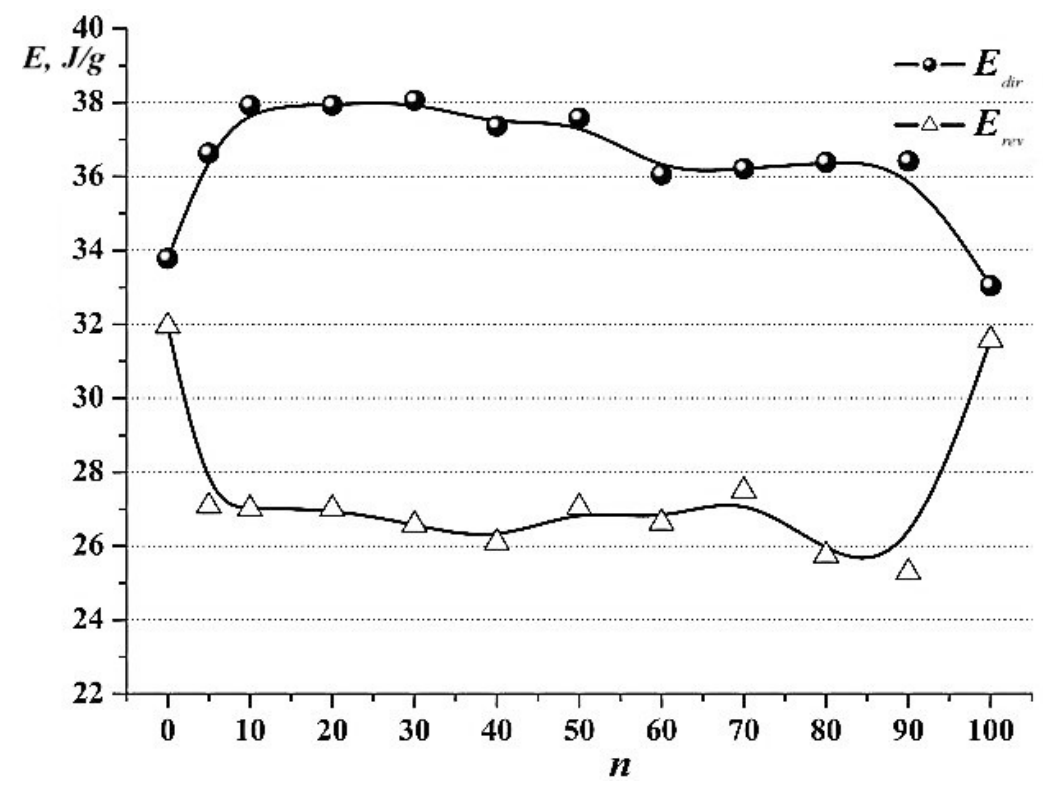

Fig. 4. The dependence of the energy of transformations on the number of heat exchanges $n$.

Using the equation of thermodynamic balance and the dependences derived from it, it is possible, in addition to the basic thermodynamic characteristics (enthalpy (H), entropy (S), transformation temperatures), to determine the elastic energies, dissipative energy, which contribute to the contribution of defects and martensitic twins. Table 3 presents the results of calculations of the thermodynamic parameters of the $\mathrm{Ti}_{50} \mathrm{Ni}_{50}$ alloy after a TC with a maximum number of cycles. 
Table 3. Thermodynamic parameters of the alloy in various states*

\begin{tabular}{|c|c|c|c|c|c|c|c|c|}
\hline State & $\begin{array}{c}\mathbf{Q}_{\text {dir }}, \\
\mathbf{J} / \mathbf{g}\end{array}$ & $\begin{array}{c}\text { Qrev, } \\
\mathbf{J} / \mathbf{g}\end{array}$ & $\begin{array}{l}\Delta S^{A \rightarrow M}, \\
\mathbf{J} /\left(\mathbf{g}^{*} \mathbf{K}\right)\end{array}$ & \begin{tabular}{|l}
$\Delta E_{e l}^{A-\rightarrow M}$ \\
$\mathbf{J} /\left(\mathbf{g}^{*} \mathbf{K}\right)$
\end{tabular} & $\begin{array}{c}\Delta E_{e l}^{M-A}, \\
\mathbf{J} /\left(\mathbf{g}^{*} \mathbf{K}\right)\end{array}$ & $\begin{array}{c}\Delta E_{e l}^{d}, \\
\mathbf{J} /\left(\mathbf{g}^{*} \mathbf{K}\right)\end{array}$ & $\begin{array}{c}\Delta H^{A \rightarrow M}, \\
\mathbf{J} / \mathbf{g}\end{array}$ & $\Delta Q^{v}, \mathrm{~J} / \mathrm{g}$ \\
\hline CG & 34,4 & $-35,3$ & 0,1090 & 2,474 & 1,744 & 0 & 39,207 & 2,539 \\
\hline $\begin{array}{l}\text { CG+TC } \\
(n=100)\end{array}$ & 32,8 & $-33,9$ & 0,1046 & 2,291 & 1,14 & 0,371 & 37,253 & 2,233 \\
\hline
\end{tabular}

* The error in determining the heat of conversion is $\pm 0.5 \mathrm{~J} / \mathrm{g}$

According to the calculations, a change in the dissipative energy determines the change in the hysteresis of the transformations.

\section{Conclusions}

1. Thus, the influence of thermal cycling on the structure and thermodynamic parameters of the TiNi alloy was considered in the work. Under the influence of multiple martensitic transformations, the width of the martensitic plates decreases in the structure of the $\mathrm{Ti}_{50} \mathrm{Ni}_{50}$ alloy.

2. It has been found that with the maximum number of cycles in the martensite twins, compound nanotwins (001)B19', several nanometers in size, are formed to reduce the level of internal stresses.

3. As a result of TCs, the temperatures of martensitic transformations and peak temperatures first shift to the region of lower temperatures, which is associated with phase hardening in the material, and, starting from the 80th cycle, the stage of temperature increase begins. Thermodynamic calculations confirm that thermal cycling leads to phase hardening.

This work was supported by the Grant of the Bashkortostan Republic of Russian Federation to young scientists (№28 GR from 07.03.2019).

\section{References}

1. V. Brailovski, S. Prokoshkin, P. Terriault, F. Trochu et al., Shape memory alloys: fundamentals, modeling and applications (ETS Publ., Montreal, 2003)

2. K. Otsuka, C.M. Wayman et al., Shape memory materials (Cambridge University Press, Cambridge, 1999)

3. V.N. Khachin, V. G. Pushin, V. V. Kondratiev, Titanium nickelide, structure and properties (Nauka, Moscow, 1992) (in Russian)

4. V.E. Gunter, Medical Materials and Implants with Shape Memory (TSU, Tomsk, Russia,1998)

5. S. Miyazaki, T. Imai, Y. Igo, K. Otsuka, Acta Metall. 34, 2045-2051 (1986)

6. V.Y. Erofeev, L.A. Monasevich, V.A. Pavskaya, Y.I. Paskal, Fiz. Met. Metalloved. 53, 963-965 (1982)

7. Y.P. Mironov, P.G. Erokhin, S.N. Kulkov, Izvestiya vuzov. Fizika 2, 100-106 (1997)

8. S. Belyaev, N. Resnina, A. Sibirev, J. Alloys Compd. 542, 37-42 (2012)

9. S. Belyaev, N. Resnina, R. Zhuravlev, J. Alloys Compd. 577, 232-236 (2013)

10. S. Belyaev, N. Resnina, Int. J. Mater. Res. 104, 11-17 (2013)

11. A.A. Churakova, D.V. Gunderov, Acta Metallurgica Sinica (English Letters) 28(10), 1230-1237 (2015)

12. A.A. Churakova, D.V. Gunderov, Physics of metals and metal science 117 (1), 105112 (2016) 